formación disponible de los 20 países miembros de la Sociedad Latinoamericana de Nefrología e Hipertensión, en los que vive $97 \%$ de la población de América Latina.

La tasa de tratamiento de la IRC terminal ha aumentado hasta llegar a 478,2 pacientes por millón de habitantes (pmh). Al 31 de diciembre de 2005 había 147158 pacientes en hemodiálisis permanente (44\% de ellos en Brasil), 50251 en diálisis peritoneal (65\% en México) y más de 52000 pacientes vivían con un riñón trasplantado. Simultáneamente se ha observado un aumento en la incidencia: de 33,3 pmh en 1993 a 167,5 en 2005. Las mayores prevalencias (más de 600 pmh) se encontraron en Puerto Rico, Chile, Uruguay y Argentina; seguidos de Colombia, Brasil, México, Panamá y Venezuela, con prevalencias de 300-600 pmh; y tasas significativamente más bajas (menores de 50 pmh) en el resto de los países. Solamente en Puerto Rico se encontró una tendencia a la estabilización de la tasa de incidencias (310 pmh en 2005).

La diabetes continúa siendo la principal causa de IRC terminal (30,3\% de los nuevos casos), con la mayor incidencia en Puerto Rico (65\%), México (51\%), Venezuela (42\%) y Colombia (35\%).

La tasa de trasplante ha aumentado de 3,7 pmh en 1987 a 15 pmh en 2005. En 2005 se realizaron 7968 trasplantes de riñón en los 20 países analizados. La mayor cifra acumulada de trasplante se concentra en Argentina (98 541), Brasil (43 405) y México (18 444). Existen programas de trasplante doble en Argentina, Brasil, Chile, Colombia, México y Uruguay. La proporción de donantes fallecidos se ha mantenido cercana a $50 \%$ en los últimos años, pero fue superior a $70 \%$ en Argentina, Chile, Colombia, Cuba, Perú y Uruguay. En contraste, todos los donantes de El Salvador, Honduras, Nicaragua y República Dominicana eran personas vivas.

Las diferencias en la situación económica de los países analizados también influyen en el nivel de acceso al tratamiento para la IRC terminal. Mientras la cobertura abarcaba a $100 \%$ de los pacientes diagnosticados en Argentina, Brasil, Chile, Cuba, Puerto Rico, Uruguay y Venezuela, la cobertura en el resto de los países varió de $56 \%$ en Colombia a solo 25\% en Perú y Paraguay.

En la actualidad se desconocen la prevalencia exacta de IRC en América Latina y la proporción de pacientes que avanzarían a su estadio terminal. En 11 de 14 países investigados funcionan programas nacionales de detección de IRC. Estos programas deben concentrar su atención en los pacientes con mayor riesgo (hipertensión arterial, diabetes y obesidad) y deben tomar algunas medidas simples, como el control de la tensión arterial y algunos indicadores bioquímicos. Para lograr el éxito, estos programas deben llegar a los servicios de atención primaria y educar a la población a través de los medios de comunicación con la participación activa de los nefrólogos. (Cusumano AM, González Bedat MC. Chronic kidney disease in Latin America: time to improve screening and detection. Clin J Am Soc Nephrol. 2008;3:594-600.)

\section{El periodismo científico en América Latina, ¿se informa correctamente a la población?}

La comunicación de los nuevos hallazgos científicos a través de los medios de prensa puede ayudar a la población general a conocer y aprovechar los adelantos de la ciencia. En el caso de la información relacionada con la salud pública, pequeñas distorsiones pueden llevar a cientos o miles de personas a prácticas o acciones dañinas para su salud personal o colectiva. En América Latina, pocos estudios han analizado de manera sistemática y con rigor el complicado proceso de llevar la información publicada en las revistas científicas a los medios masivos de comunicación.

En este artículo se analiza el proceso de adaptación de la información científica publicada por revistas científicas arbitradas a textos periodísticos en la Región. En un lapso de 30 días se identificaron 482 artículos periodísticos relacionados con 17 artículos científicos originales. De ellos se tomaron los publicados en cuatro periódicos latinoamericanos de gran circulación que tienen redacciones especializadas en ciencia (La Nación, de Argentina; El Mercurio, de Chile; Reforma, de Mexico; El Comercio, de Ecuador; O Globo, Folha de São Paulo y Jornal do Commercio/Pernambuco, de Brasil), relacionados con dos artículos publicados en Science y dos publicados en Nature.

Con relación a uno de los artículos originales que informaba la secuenciación del genoma de la rata, todos los periódicos ofrecieron información directa y objetiva del hecho científico y tres de ellos se refirieron al artículo científico en su encabezado. Todos informaron sobre la aplicabilidad de la investigación y no se observaron señales de sensacionalismo.

En cuanto a un artículo que daba cuenta del descubrimiento de restos fósiles de un gato en Chipre, tres de los periódicos emplearon en sus títulos expresiones poco científicas y que desvirtuaban su esencia, como "9 500 años de gatos en casa".

En tres de los periódicos, la información sobre el descubrimiento en África del Sur de un collar que data de hace 75 millones de años se centró en el valor inestimable de la joya y sus aristas más pueriles, sin profundizar en la trascendencia científica e histórica del hallazgo. 
El nacimiento de la rata Kaguya por partenogénesis (sin fecundación) presentó particularidades muy interesantes que se reflejaron en los titulares: "Revolución genética: japoneses generaron ratón sin padre" (El Mercurio) o "¿Serán prescindibles los hombres?" (La Nación). Nada se dijo acerca de que los investigadores construyeron 598 oocitos no viables antes de que finalmente sobrevivieran dos, de uno de los cuales nació Kaguya. En ninguno de los periódicos analizados se mencionó la necesidad de la contribución paterna para mantener el linaje -más bien sus versiones se centraron en todo lo contrario-, a pesar de que los autores resaltaron explícitamente este hecho en la última frase de las conclusiones, espacio reservado para exponer los juicios principales.

Además, se identificaron errores e incoherencias, particularmente en los datos numéricos, que reflejan descuido y premura al redactar los artículos periodísticos. En algunos casos era evidente que las distorsiones se debían al descuido o al ajuste de la información a la corriente ideológica del autor.

La iniciativa de las revistas científicas de enviar comunicados de prensa a los medios tiene una buena aceptación por parte de los periodistas y puede tener un notable impacto en la cobertura de la información científica. Sin embargo, el proceso de adaptación de la información científica al lenguaje periodístico implica transformar el léxico, el estilo y la forma de argumentar o explicar los resultados. Lamentablemente, con frecuencia esto va acompañado de la adición o la supresión de información, alteraciones de los datos, cambios en la jerarquía y el énfasis correcto de la información, malinterpretaciones del impacto social esperado, etc.

Está comprobado que al llevar la información científica a los medios masivos de comunicación ocurren distorsiones. Es necesario prestar especial atención al rigor con que se lleva a la población la información científica relacionada con la salud pública. (Veneu F, Amorim LH, Massarani L. Science journalism in Latin America: how the scientific information from a scientific source is accommodated when it is transformed into a journalistic story. J Scie Comm. 2008;(1). Hallado en http://jcom.sissa. it/archive/07/01/Jcom0701\%282008\%29A03/. Acceso el 6 de mayo de 2008.)

FE DE ERRATA

\section{Trypanosoma cruzi I: único tipo del parásito tripanosómico circulante en Panamá (Rev Panam Salud Publica/Pan Am J Public Health 2008;23(5):357)}

La redacción llama la atención de los lectores sobre la siguiente errata aparecida en la versión publicada de este artículo de la sección de Instantáneas:

P. 357. Versión equivocada: "Diversos autores han atribuido esta heterogeneidad a la variabilidad genética del trematodo Trypanosoma cruzi". Versión correcta: "Diversos autores han atribuido esta heterogeneidad a la variabilidad genética del protozoario Trypanosoma cruzi". 